\title{
O prazo decadencial das contribuições sociais do sistema de seguridade social
}

Marcos de Queiroz Ramalho'

\section{Resumo}

Este pequeno ensaio pretende, sem querer esgotar o assunto, discutir o prazo decadencial prevista na lei no 8.212/91 - principal lei de plano de custeio da seguridade social. Para tanto, aborda-se o conceito do instituto da decadência, a natureza jurídica das contribuições sociais e o prazo legal para o lançamento das contribuições sociais, sem esquecer do posicionamento jurisprudencial.

Palavras Chave: Contribuições sociais; Decadência; Inconstitucionalidade.

\section{Natureza jurídica das contribuições sociais}

Antes de entrarmos no cerne da questão, é de bom alvitre deixar clara a natureza jurídica das contribuições sócias, que tem como nascedouro o texto constitucional vigente.

O Supremo Tribunal Federal já declarou que as contribuições sociais recolhidas ao INSS pertencem a o regime tributário, porque está inserido dentro do sistema tributário nacional.

Analisando a questão, Aliomar Balleiro ${ }^{2}$, devidamente atualizado, coloca que a partir da CF/88 há a exclusividade da competência de criar contribuições sociais, deixando claro de uma vez por todas o caráter tributário, sendo que inadmissível que se faça interpretação de forma isolada, sem a conjugação das demais normas e princípios constitucionais.

É o que também pensa Geraldo Ataliba", asseverando que "a Constituição de 1988 resgatou a boa doutrina tradicional e restaurou a certeza quanto à inquestionabilidade do cunho tributário das contribuições (parafiscais ou não)."

1 Advogado especializado na área de Previdência Social. Mestre em Direito Previdenciário pela PUC-SP, professor de Direito Previdenciário na Universidade Estadual de Londrina, professor na pós-graduação em Direito do Estado na UEL e de Direito Previdenciário na BB\&G Sociedade de Ensino - marcosqr@uol.com.br.

2 BALEEIRO, Aliomar. Limitações Constitucionais ao Poder de Tributar. 7. ed. Rio de Janeiro: Forense, 2002. p. 593.

3 ATALIBA, Aliomar. Hipóteses de Incidência Tributária. 6. ed. 2 T. São Paulo: Malheiros, 2001. p. 198. 
Importante ainda destacar a ressalva exposta por Carlos Alberto Pereira de Castro e João Batista Lazzari, inclinaram-se no seguinte sentido ${ }^{4}$ :

Filiamo-nos à orientação que predominou na doutrina e na jurisprudência após a Constituição de 1988, de que as contribuições destinadas ao financiamento da Seguridade Social possuem natureza jurídica tributária, pois estão sujeitas ao regime constitucional peculiar aos tributos, ressalvada apenas a previsão do $\S 6$. do art. 195 da Carta Magna.

Wagner Balera ao discutir sobre o referido tema, colocando uma pá de cal, assim preleciona ${ }^{5}$ :

São frágeis, pois, os argumentos com que essa doutrina pretende criar uma figura jurídica nova, diferente dos tipos de exação existentes, com o fito de apartá-las das regras constitucionais aplicáveis aos tributos.

Da análise dos artigos 149, 165, § 5ำ, 167, VI e VII, 194 e 195 da nossa Lei Suprema, chega-se a conclusão que mesmo, obedecendo as regras do regime tributário, há certas diferenças entre as contribuições sociais e os impostos propriamente ditos, mas que não lhe retiram a natureza jurídica tributária.

Esse introdutório é de suma importância porque vai balizar todos os demais tópicos deste trabalho.

\section{Do conceito da decadência}

A decadência e a prescrição são institutos estudados com todo o cuidado pela grande parte da doutrina, para evitar celeumas desnecessárias, uma vez que por vezes, o próprio diploma legal que rege tais institutos não as diferencia.

O próprio Código Civil de 1916, não distinguia o primeiro do segundo, criando verdadeiras batalhas jurídicas nos tribunais pátrios.

Sabiamente a lei no 10.4062/2002(novo código civil) separou tais institutos criando capítulo próprio para a decadência, mas sem conceituá-la.

Para tanto, buscamos no escólio do civilista Silvio Rodrigues, que admite que, quanto aos efeitos, a diferenciação é clara, mas "difícil tem ela se mostrado, quando se

4 CASTRO, Alberto Pereira de. Manual de Direito Previdenciário. 4.ed. São Paulo: LTr, 2003. p. 196.

5 LAZZARI, João Batista. Curso de Direito Previdenciário. 5. ed. São Paulo: LTr, 2002. p. 48. 
procurara estabelece-la, tendo em vista a natureza ou essência de cada uma das instituições." ${ }^{6}$

Segundo referido autor enquanto a prescrição está voltada ao direito de ação no instituto da decadência o que falece é o próprio direito.

Mas tal conceito de ordem civilista não é suficiente quanto o objeto do estudo é o direito público, mais especificamente o direito tributário.

O professor Eurico Marcos Diniz de Santi ${ }^{7}$ se propôs ao estudar profundamente a decadência e prescrição no Direito Tributário. Para ele "a decadência e a prescrição do direito do fisco não comportam a mesma amplitude de dissensão mesma complexidade que verificamos no direito privado."

Seguindo a linha de pensamento desse estudioso a decadência deve ser vista, a par da prescrição, como norma individual e concreta, determinando, exemplificativamente, que novo diploma legal (sobre decadência) só possa prevalecer a partir do início de sua vigência.

Para o ramo do direito tributário a decadência está ligada intimamente ao lançamento dos tributos, dentro de suas espécies verificadas nos texto legais. Não havendo o competente lançamento no prazo legal, não pode o fisco cobrar através do executivo fiscal.

Entre as conclusões que se pode afirmar, é que para o direito tributário a fluência "in albis" da norma decadencial impede a constituição do crédito tributário por parte do fisco, de acordo com cada norma específica.

\section{Do prazo de decadência qüinqüenal - ilegalidade da decadência trintenária ou decenal}

A decadência como se sabe, é considerada uma forma de extinção do crédito tributário a teor do art. 156, V do C.T.N.

Paulo de Barros Carvalho ${ }^{8}$ em seu conhecidíssimo livro Direito Tributário leciona:

RODRIGUES, Silvio. Direito Civil. V. 1. São Paulo: Saraiva, 2004. p. 329.

SANTI, Eurico Marcos Diniz de. Decadência e Prescrição no Direito Tributário. São Paulo: Max Limonad, 2000. p. 146.

8 CARVALHO, Paulo de Barros. Direito Tributário. Fundamentos Jurídicos da Incidência. São Paulo: Saraiva, 1999. p. 202. 
Ora, o efeito extintivo previsto é o do desaparecimento do direito da Fazenda, consistente em exercer sua competência administrativa para "constituir o crédito tributário". Reconhecido o fato da decadência, sua eficácia jurídica será a de fulminar a possibilidade de a autoridade competente realizar 0 ato jurídicoadministrativo do lançamento. Sabemos que, sem efetuá-lo, não se configura o fato jurídico e, por via de conseqüência, também não se instaura a obrigação tributária.

Tal fato se dá pela decorrência do lapso temporal. Nas palavras Eurico Marcos Diniz de Santi, em sua tese de doutorado ${ }^{9}$ :

\begin{abstract}
Nas hipóteses normativas das normas decadencial ou prescricional descrevem o transcurso de tempo, qualificado pela conduta omissiva do titular do direito, contado do dies a quo fixado na legislação tributária. O acontecimento do decurso ficado na legislação tributária. O acontecimento do decurso desse prazo, no plano do suporte fictício é o evento. Os fatos decadencial ou prescricional no domínio do direito vão surgir quando esse acontecimento, que se dá no tempo histórico e no espaço social, for relatado e linguajem competente, i.e., e segundo a forma em direito admitida, ocupando o lugar de antecedente nas normas individuais e concretas da decadência ou da prescrição.
\end{abstract}

No caso sub exame, desde a lei federal no 3.807/60 que unificou o sistema previdenciário o direito decadencial era de 30 anos (segundo a posição oficial do extinto IAPAS - atual INSS).

A celeuma jurídica foi levada aos Tribunais e reiteradas decisões, chegaram ao desfecho final que o prazo decadencial das contribuições previdenciárias eram de 05(cinco) anos até o início da vigência da emenda no. $08 / 77^{10}$ :

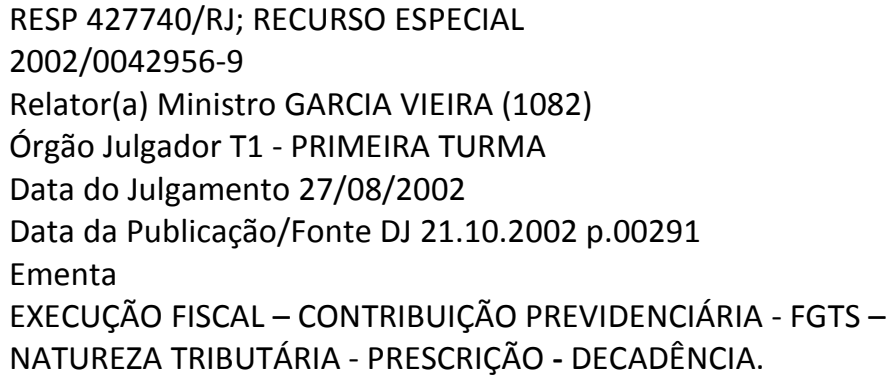
tributária até o advento da Emenda Constitucional no. 08/77, quando perderam esta característica e passaram a ser consideradas contribuições sociais, com prazos de decadência e prescrição não mais regulados pelo Código Tributário Nacional. Precedentes do STF e do STJ.

Recurso provido.

SANTI, 2000. p. 156.

10 www.stj.gov.br, acesso em 12.11.2004. 
Depreende-se tal desfecho pela simples leitura dos artigos $153^{11}$ e $154^{12}$ pelo antigo regulamento de custeio - Decreto no 83.081, de 24.01.1979.

Desde aquela época já era discutido no âmbito judicial o prazo decadencial, porque entendiam renomados doutrinadores que o prazo era qüinqüenal a vista do artigo art. 173, I e II do CTN, que passamos a reproduzir:

Art. 173. O direito de a Fazenda Pública constituir o crédito tributário extingue-se após 5 (cinco) anos, contados:

I - do primeiro dia do exercício seguinte àquele em que o lançamento poderia ter sido efetuado;

II - da data em que se tornar definitiva a decisão que houver anulado, por vício formal, o lançamento anteriormente efetuado.

Parágrafo único. O direito a que se refere este artigo extingue-se definitivamente com o decurso do prazo nele previsto, contado da data em que tenha sido iniciada a constituição do crédito tributário pela notificação, ao sujeito passivo, de qualquer medida preparatória indispensável ao lançamento.

§ 4ㅇ Se a lei não fixar prazo a homologação, será ele de cinco anos, a contar da ocorrência do fato gerador; expirado esse prazo sem que a Fazenda Pública se tenha pronunciado, considera-se homologado o lançamento e definitivamente extinto o crédito, salvo se comprovada a ocorrência de dolo, fraude ou simulação.

Nem é preciso se aprofundar quanto ao INSS se enquadrar no conceito de Fazenda Pública, se a própria autarquia-ré confessa em milhares de ações judiciais que goza das mesmas prerrogativas da União Federal.

Conseqüentemente, enquanto a nossa mais Alta Corte, entendia que a partir da Emenda Constitucional $n$ o 08/77, as contribuições não estavam mais sujeitas ao prazo do C.T.N., a doutrina quase unânime continuava no firme posicionamento que até o advento da Carta Constitucional de 1988 o INSS estava sujeito ao prazo qüinqüenal em matéria decadencial, e que para majorar tal prazo deveria por meio de diploma legal competente.

Portanto, em face da regra contida na emenda $n$ ㅇ 08/77, que passamos a reproduzir o Supremo Tribunal Federal, a partir de então, inclinou-se em sentido contrário:

Art. 21. Compete à União instituir imposto sobre:

$\S 1$ ㅇ...]

$\S 2$ 2․ A União pode instituir

11 Art. 153 Os prazos de prescrição de que goza a União aplicam-se às entidades de direito público integrante do SINPAS, ressalvado o disposto nos artigos 154 e 156.

12 Art. 154 O direito do IAPAS de receber ou cobrar importâncias devidas ao FPAS e ao FLPS prescreve em 30(trinta) anos. 
I - contribuições, observada faculdade prevista no item I deste artigo, tendo em vista intervenção no domínio econômico ou o interesse de categorias profissionais e para atender diretamente à parte da União no custeio dos encargos da previdência social.

Embora o conteúdo da emenda acima transcrita não tenha se referido expressamente ao prazo decadencial, os nossos Tribunais começaram a decidir que as contribuições sociais não deveriam obedecer ao prazo estipulado na lei tributária.

Passado pouco mais de 03(três) anos foi aprovada a lei de execução fiscal - lei no 6.830 de 22.09.80, assim disciplinando sobre as contribuições previdenciárias:

Art. 20

§ 9 O prazo para a cobrança das contribuições previdenciárias continua a ser o estabelecido no artigo 144 da lei no 3.807, de 27.08 de 1960.

Decorre pela interpretação sistemática, a bem da verdade, tratava-se de prazo prescricional e não decadencial, mas o Judiciário continuou a entender que o prazo era trintenário quanto a norma decadencial.

Com a promulgação do texto constitucional de 1988, as contribuições sociais foram dispostas dentro do sistema tributário nacional e dos princípios constitucionais que regem os tributos.

A lei no 8.212/91 conhecida como lei de custeio das contribuições sociais, com o afã de evitar novos entraves jurídicos, estabeleceu novo prazo para o ato decadencial:

\footnotetext{
Seção VII

Da Decadência e Prescrição

Art. 70. O direito da Seguridade Social de apurar e constituir seus créditos extinguese após 10 (dez) anos contados:

I - do primeiro dia do exercício seguinte àquele em que o crédito poderia ser sido constituído

II - da data em que se tornar definitiva a decisão que houver anulado, por vício formal, a constituição de crédito anteriormente efetuada.
}

Tal dispositivo é manifestamente inconstitucional, por não respeitar o nascimento de uma nova ordem constitucional, instituindo prazo diferenciado da lei tributária.

O Código Tributário Nacional (Lei no 5.172/66), apesar de se tratar de Lei Federal, foi recepcionado pela nossa Lei Suprema atual como lei-complementar, no aspecto formal. 
Já a lei de custeio da Seguridade Social assim não pode ser aceita. Também é assente que a decadência nos termos ora estudado é matéria específica do Direito Tributário.

E como se sabe matéria tributária só pode ser alterada por lei-complementar, conforme comando expresso do texto constitucional:

Art. 146. Cabe à lei complementar:

I - dispor sobre conflitos de competência, em matéria tributária, entre a União, os Estados, o Distrito Federal e os Municípios;

II - regular as limitações constitucionais ao poder de tributar;

III - estabelecer normas gerais em matéria de legislação tributária, especialmente sobre:

a) definição de tributos e de suas espécies, bem como, em relação aos impostos discriminados nesta Constituição, a dos respectivos fatos geradores, bases de cálculo e contribuintes;

b) obrigação, lançamento, crédito, prescrição e decadência tributários;

c) adequado tratamento tributário ao ato cooperativo praticado pelas sociedades cooperativas.

Novamente o professor EURICO MARCOS DINIZ DE SANTI, tendo a mesma opinião jurídica de Sacha Calmon Navarro Coelho, é categórico ao apontar tamanha inconstitucionalidade ${ }^{13}$ :

Entretanto, diversamente do Código Tributário Nacional e da Lei de Execução Fiscal, a lei $n$ o 8.212, de 24 de julho de 1991 foi produzida sob pleno vigor do art. 146, III b da Constituição Federal de 1988, que expressamente determina que matéria de decadência e prescrição é de competência restrita à esfera da lei complementar.

Por não se tratar de lei complementar, entendemos que os dispositivos desta Lei afrontam expressamente a Carta Magna, apresentando-se incompatíveis com os requisitos constitucionais para produção dessa categoria de normas jurídicas, devendo, destarte, ser submetidos ao respectivo controle de constitucionalidade para cumprir o disposto no Texto Supremo.

Corroborando essa linha de pensamento o Superior Tribunal de Justiça ${ }^{14}$, em caso idêntico, assim acordou:

Acordão Origem: STJ - SUPERIOR TRIBUNAL DE JUSTIÇA

Classe: RESP - RECURSO ESPECIAL - 202203

Processo: 199900069064 UF: MG Órgão Julgador: SEGUNDA

TURMA Data da decisão: 26/10/1999 Documento: STJ000319853

13 SANTI, 2000. p. 94.

14 www.cjf.gov.br, acesso em 20.09.2004. 


$\begin{array}{ll}\text { Fonte } & \text { DJ DATA:13/12/1999 PÁGINA:134 } \\ \text { Relator(a) } & \text { FRANCISCO PEÇANHA MARTINS } \\ \text { Decisão } & \text { Vistos, relatados e discutidos estes autos, acordam os Ministros da } \\ & \text { Segunda Turma do Superior Tribunal de Justiça, na conformidade } \\ & \text { dos votos e das notas taquigráficas a seguir, por unanimidade, } \\ & \text { negar provimento ao recurso. Votaram com o Relator os Ministros } \\ & \text { Paulo Gallotti e Francisco Falcão. Ausente, ocasionalmente, a Sra. } \\ & \text { Ministra Eliana Calmon. } \\ & \text { PROCESSUAL CIVIL. EXECUÇÃO FISCAL. CONTRIBUIÇÃO } \\ \text { Ementa } & \text { PREVIDENCIÁRIA. EMBARGOS DO DEVEDOR. DECADÊNCIA. 1. Com } \\ & \text { o advento da Lei 6.830/80, restabelecendo o art. 144 da Lei } \\ & \text { 3.807/60, o prazo prescricional para cobrança de contribuições } \\ & \text { previdenciárias é trintenário, porém, permanece quinquenal o } \\ & \text { prazo de decadência, que se concretiza, se ultrapassado, a partir de } \\ & \text { quando deve ser constituído o crédito. 2. Recurso especial } \\ & \text { conhecido, porém, improvido. }\end{array}$

No mesmo sentido, decidiu o STJ, da lavra do Ministro Francisco Peçanha Martins:

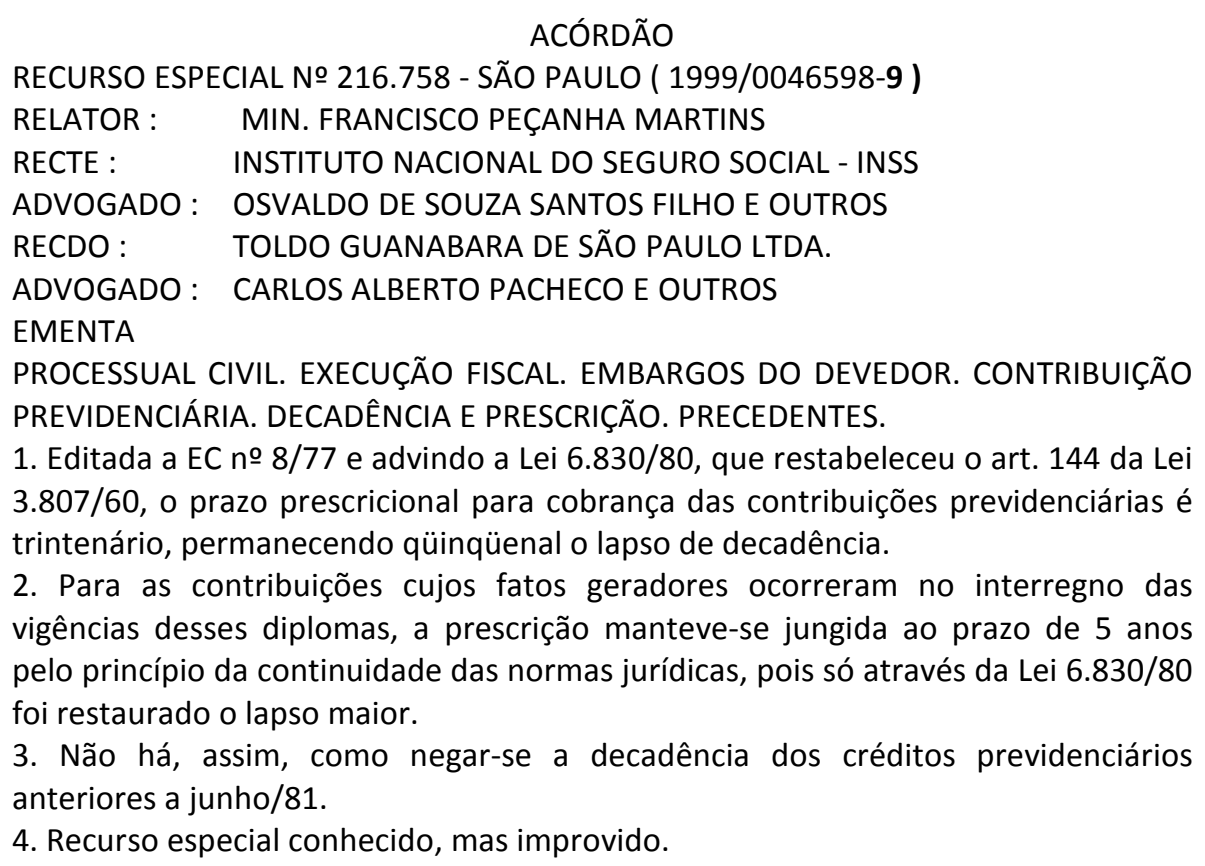

Por fim, o Tribunal Regional Federal - 4ạ. Região também tem adotado a minha linha de entendimento: ${ }^{15}$

E M E N T A

TRIBUTÁRIO. MANDADO DE SEGURANÇA. CERTIDÃO NEGATIVA DE DÉBITO. CONTRIBUIÇÃO PREVIDENCIÁRIA. DECADÊNCIA. SÚMULA 108, TFR.

1. É de cinco anos o prazo decadencial para constituição do crédito previdenciário (Súmula 108, TFR).

15 www.trf4.gov.br, acesso em 30.09.2004, Apelação em Mandado de Segurança em no o 95.04.51717-0-RS. 
2. Apelação e remessa oficial improvidas.

A C Ó R D Â O

Vistos e relatados estes autos, em que são partes as acima indicadas, a 1a Turma do Tribunal Regional Federal da 4ạ Região, por unanimidade, decidiu negar provimento à apelação e à remessa oficial, nos termos do voto do Relator. Porto Alegre, 04 de agosto de 1998 (data do julgamento). (DJ2 de 26.08.98, p. 747).

Sendo considerada inconstitucional deve prevalecer a regra do código tributário nacional (lei no. 5.172/66), que são de 05 (cinco) anos para o lançamento do crédito tributário, conforme estatuído no artigo 173.

\section{Conclusões}

4.1. As contribuições sociais vertidas em favor da seguridade social têm natureza jurídica tributária, devendo obedecer as normais gerais do regime tributário nacional, com a exceção do princípio da anterioridade que são de 90(noventa) dias.

4.2. Até a emenda constitucional no 08, de 14.04.1977 as contribuições sociais em favor da seguridade social tem natureza jurídica tributária, devendo obedecer o prazo decadencial.

4.3. A partir da emenda $n$ ㅇ 08/77 até o início da lei $n$ o 8.212/91 o Supremo Tribunal Federal pacificou o entendimento que as contribuições previdenciárias não estavam sujeitas ao prazo decadencial previsto no código tributário nacional.

4.4. O artigo 45 da lei no 8.212/91 deve ser considerado parcialmente inconstitucional quanto ao prazo decadencial de 10(dez) anos, devendo prevalecer o prazo qüinqüenal estabelecido pela lei no 5.172/66 - CTN.

\section{Referências}

ATALIBA, Geraldo. Hipótese de Incidência Tributária. 6. ed. 2. T. São Paulo: Malheiros, 2001.

BALERA, Wagner. Curso de Direito Previdenciário. 5. ed. São Paulo: LTr, 2002.

BALEEIRO, Aliomar. Limitações Constitucionais ao Poder de Tributar. 7. ed. Rio de Janeiro: Forense, 2002.

CARVALHO, Paulo de Barros. Direito Tributário. Fundamentos Jurídicos da Incidência. São Paulo: Saraiva, 1999. 
Teoria da Norma Tributária. São Paulo: Max Limonad, 2002.

CASTRO, Carlos Alberto Pereira; LAZZARI, João Batista. Manual de Direito Previdenciário. 4. ed. São Paulo: LTr, 2003.

RODRIGUES, Silvio. Direito Civil. São Paulo: Saraiva, 2004. v. 1.

SANTI, Eurico Marcos Diniz de. Decadência e Prescrição no Direito Tributário. São Paulo: Max Limonad, 2000. 